\title{
Tandem Interplay of Host-guest Interaction and Photoresponsive Supramolecular Polymerization to 1D and 2D Functional Peptide Materials
}

\author{
Jojo P. Joseph, ${ }^{\xi}$ Ashmeet Singh, ${ }^{\xi}$ Deepika Gupta, Chirag Miglani and Asish Pal* \\ Institute of Nano Science and Technology, \\ Phase 10, Sector 64, Mohali, Punjab, 160062 (India) \\ Email: apal@inst.ac.in \\ $\xi$ These authors contribute equally
}

Table of Contents

$\begin{array}{ll}\text { 1. Materials and Methods } & \text { S-2 }\end{array}$

2. Synthesis and Characterization of peptide, $1 \quad$ S-3

3. Monitoring Host-guest complexation by ${ }^{1} \mathrm{H}$ NMR $\quad$ S-5

4. Monitoring photodimerization by ${ }^{1} \mathrm{H}$ NMR $\quad$ S-8

5. Monitoring photodimerization by UV spectroscopy S-9

$\begin{array}{lr}\text { 6. Multi-step self-assembly of peptide, } 1 & \text { S-10 }\end{array}$

$\begin{array}{ll}\text { 7. Thioflavin-T binding and confocal studies } & \text { S-12 }\end{array}$

$\begin{array}{ll}\text { 8. FTIR studies } & \text { S-13 }\end{array}$

$\begin{array}{ll}\text { 9. X-ray diffraction studies } & \text { S-13 }\end{array}$

10. Generation of the Seeds $\quad$ S-14

11. Seeded Supramolecular Polymerization $\quad$ S-15

12. Formation of hydrogels $\quad$ S-18

$\begin{array}{lr}\text { 13. } \mathrm{MoS}_{2} \text { Exfoliation study } & \text { S-19 }\end{array}$

$\begin{array}{lr}\text { 14. References } & \text { S-20 }\end{array}$ 


\section{Materials \& Methods:}

All Fmoc protected amino acids, activator (diisopropyl carbodiimide), piperazine, triisopropylsilane, anisole, 1,2-ethanedithiol and thioflavin-T (ThT) were purchased from Sigma Aldrich. 4methylcoumarin carboxylic acid was synthesized according to previous literature method. ${ }^{1}$ Oxyma, Fmoc-Rink amide MBHA resin, HPLC grade acetonitrile, water, ethanol, and DMF were obtained from Merck. Trifluoroacetic acid (TFA) and Hexafluoroisopropanol (HFIP) was purchased from SRL and TCI chemicals respectively.

Solid Phase Peptide Synthesis was performed in Liberty Blue CEM, Matthews, NC, USA and the synthesized peptide was characterised using reverse phase C18 column Waters HPLC coupled with QTOF MS detector. UV spectra was recorded using Shimadzu UV 6000 UV-vis spectrophotometer in a wavelength range of 800 to 200 . NMR spectra were acquired on a $400 \mathrm{MHz}$ Bruker ( $400 \mathrm{MHz}$ for ${ }^{1} \mathrm{H}-$ NMR). The chemical shifts are reported in ppm downfield of tetramethylsilane using the resonance of the deuterated solvent as internal standard. CD spectra were recorded using JASCO J-1500 Circular Dichroism Spectrometer, Easton, MD, USA. The wavelength range was selected from $195 \mathrm{~nm}$ to 400 $\mathrm{nm}$ with a scan speed of $100 \mathrm{~nm} \mathrm{~min}{ }^{-1}$ using $2 \mathrm{~mm}$ path length CD quartz cuvette. FTIR spectra were recorded in $\mathrm{CaF}_{2}$ cell using a Cary 600 series spectrometer from Agilent technologies. The samples were drop casted on silicon wafer and AFM height images were recorded using tapping mode on a Bruker Multimode 8 scanning probe microscope with silicon cantilever. For obtaining the fluorescence images of the Thioflavin-T (ThT) stained nanostructures the confocal laser scanning microscope LSM 880 (Carl Zeiss) equipped with a confocal detector was used. An objective lens with a 100x magnification and the fixed laser line $488 \mathrm{~nm}$ was used for excitation. Fluorescence emission spectra were recorded using FS5 spectrofluorometer from Edinburgh instruments. TEM images were recorded using JEOL JEM 2100 TEM with a Tungsten filament at an accelerating voltage of $120 \mathrm{kV}$. XRD spectra were recorded using Bruker D8 advance Powder X-ray Diffractometer operated at $20 \mathrm{~mA}$ current and $40 \mathrm{KV}$ using $\mathrm{Cu} \mathrm{K} \alpha$ source with wavelength of $1.54 \AA$. The linear viscoelastic region, storage modulus, loss modulus and thixotropic studies were calculated using a Modular Rheometer, MCR302 (AntonPaar, Austria) using cone plate (CP25-2) geometry at a measuring distance of $0.2 \mathrm{~mm}$ at $25^{\circ} \mathrm{C}$. Raman spectra were collected in WITEC Focus Innovations Alpha 300 Raman confocal microscope with an excitation laser wavelength of $532 \mathrm{~nm}$. 


\section{Synthesis and Characterization of peptide 1:}

Microwave Automated Solid Phase Peptide Synthesizer (Liberty Blue CEM, Matthews, NC, USA) was used to synthesize peptide 1. Fmoc-Rink Amide MBHA Resin was first swelled in dimethylformamide (DMF) for 30 minutes. All Fmoc protected amino acids were weighed as per the desired scale of the reaction followed by dissolving in required DMF solution. Deprotection of Fmoc group from the amino acid was achieved by using $20 \%$ piperazine in DMF containing $10 \%$ ethanol in the microwave reactor. Required mass of piperazine was vortexed in $10 \%$ of ethanol followed by addition of the remaining 90\% of DMF for complete solubilization. Diisopropylcarbodiimide (DIC, activator) and oxyma (activator base) in DMF, were used as activators for the coupling reaction between acid and amine to form the peptide bond. A cycle of coupling, deprotection steps was repeated to synthesize the required peptide anchored to the resin. The peptide was then cleaved from the resin upon shaking with a cocktail solution, that is, a mixture of trifluoroacetic acid (TFA)/ triisopropylsilane (TIPS)/ water/ 1, 2ethanedithiol (EDT) (95: 2: 2: 1, v/v/v/v) for $3 \mathrm{~h}$ at room temperature. The resin was then filtered and the filtrate containing desired peptide and excess TFA was evaporated. The peptide 1 was then precipitated from cold diethyl ether and dried to obtain white powder. The peptide was purified by RP-HPLC using a Waters Semi-Preparative binary HPLC system using a C18-reverse phase column with an acetonitrile-water mobile phase containing $0.1 \%$ TFA. It was dissolved in minimum amount of HFIP and dried once again. This erased any assembly history of the peptides during lyophilisation/freeze drying process. The purified peptide was confirmed by ESI-MS recorded with Waters HPLC Q-TOF mass instrument. LCMS (ESI) m/z: $\mathrm{C}_{50} \mathrm{H}_{67} \mathrm{~N}_{9} \mathrm{O}_{10}$ Calculated 954.12; found 954.70. 


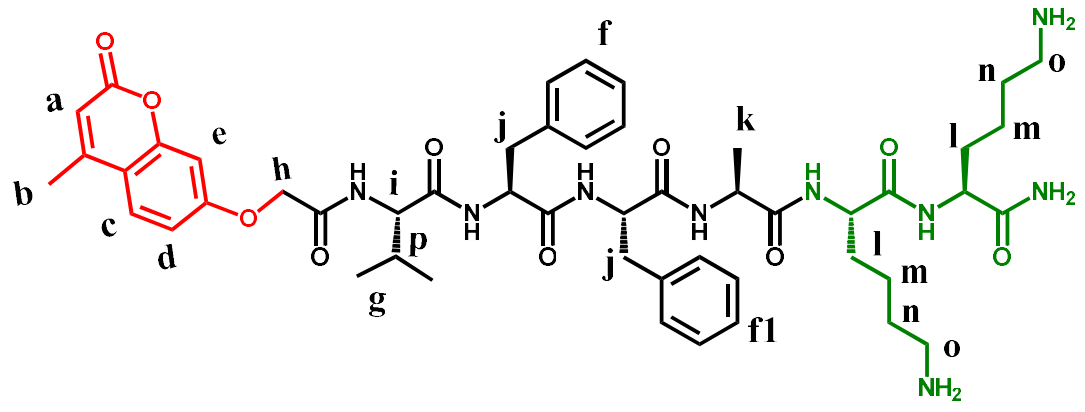
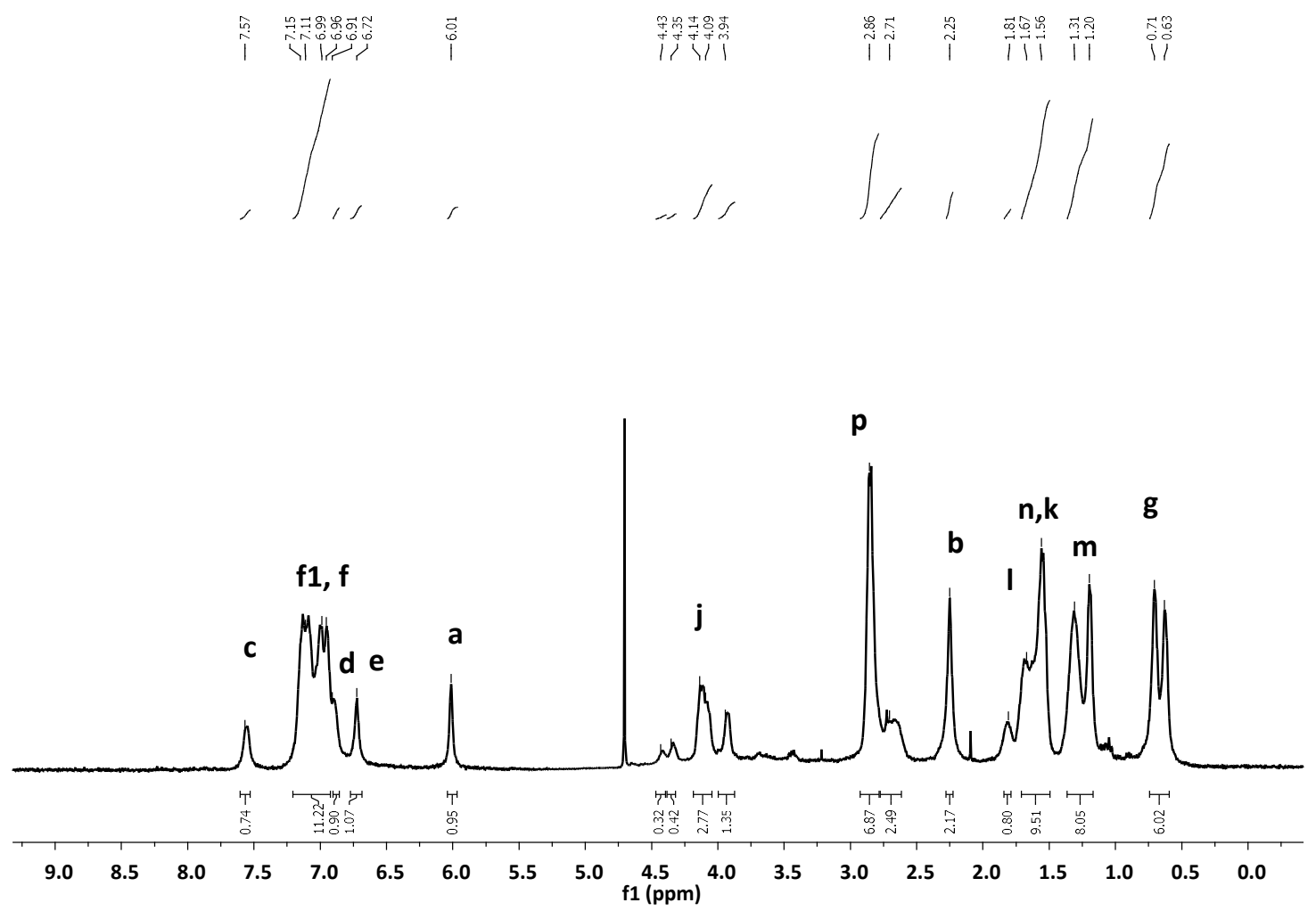

Figure S1: ${ }^{1} \mathrm{H}$ NMR of peptide $1(10 \mathrm{mM})\left(400 \mathrm{MHz}, \mathrm{D}_{2} \mathrm{O}, 298 \mathrm{~K}\right)$ 


\section{Monitoring host-guest complexation by ${ }^{1} \mathrm{H}$ NMR}

$\gamma-\mathrm{CD}(\mathrm{H})$ was titrated with $1(\mathrm{G})$ in the ratio $\mathrm{H}: \mathrm{G}$ from 9:1 to 1:9, while keeping total concentration at $10 \mathrm{mM}$ and ${ }^{1} \mathrm{H}$ NMR was measured. The variation in chemical shift was plotted against a function of molar ratio of either host or guest molecules to obtain Job's plot, which gives idea about complexation stoichiometry.
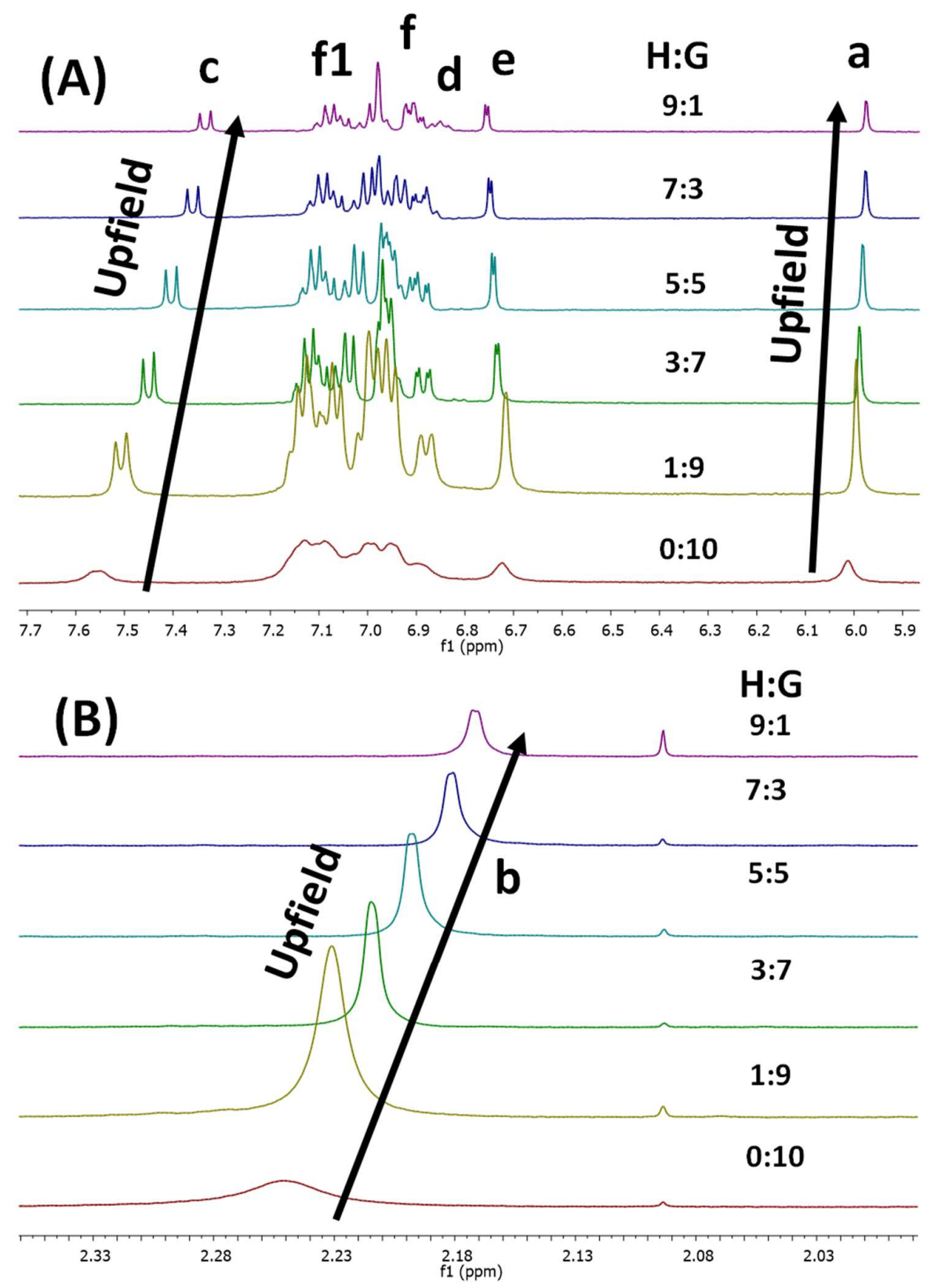

Figure S2: Partial ${ }^{1} \mathrm{H}$ NMR spectra of $\gamma-\mathrm{CD}(\mathrm{H})$ titrated with $1(\mathrm{G})$ solution at different ratios. The total concentration was kept at $10 \mathrm{mM}$. The upfield shifts of (A) $\boldsymbol{a}, \boldsymbol{c}$ protons and (B) methyl $\boldsymbol{b}$ protons of the 4-methylcoumarin moiety in $1(G)$ with increasing host was noted. 

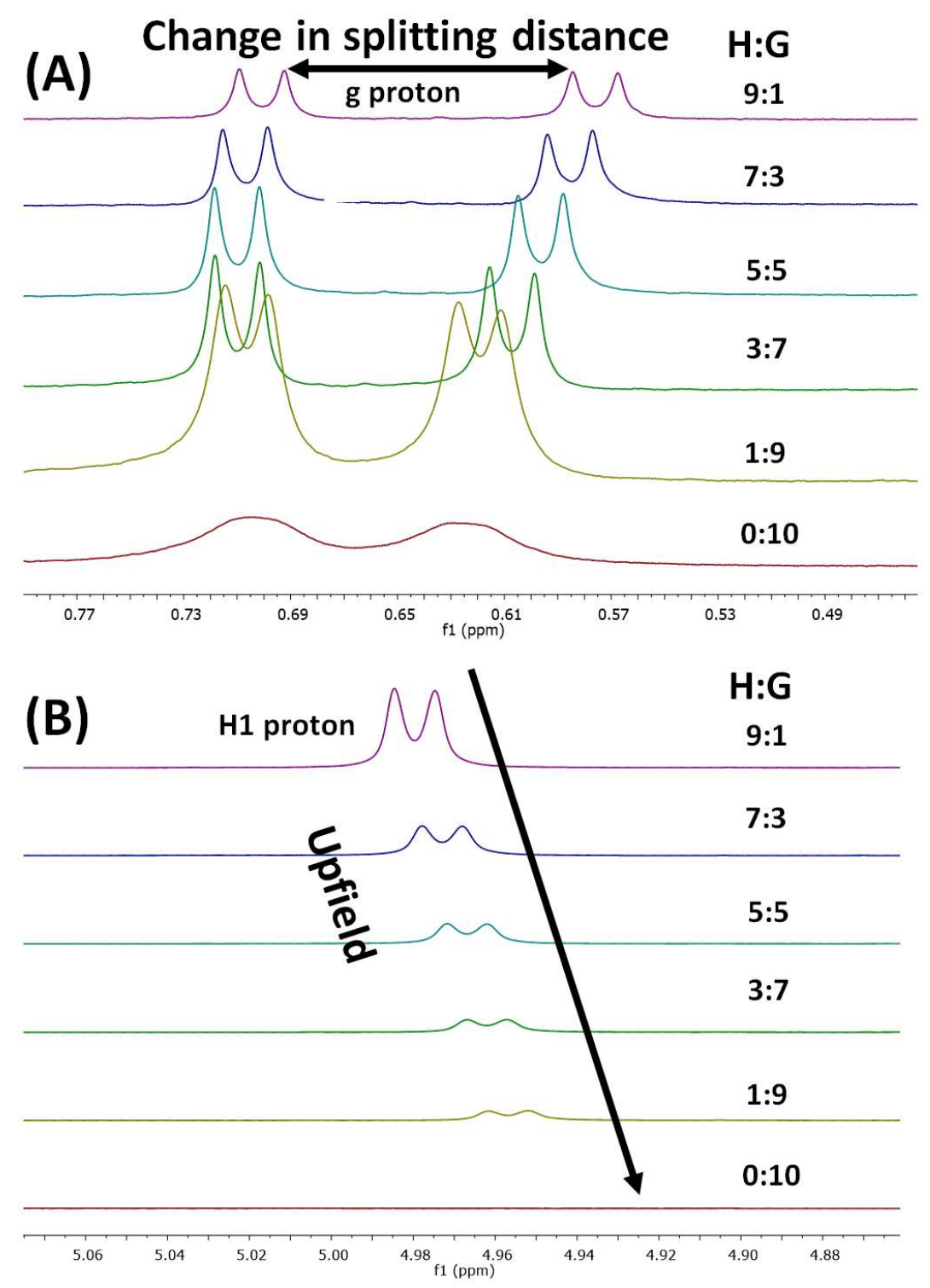

Figure S3: Partial ${ }^{1} \mathrm{H}$ NMR spectra of $\gamma-\mathrm{CD}(\mathrm{H})$ titrated with $1(\mathrm{G})$ solution at different ratios. The total concentration was kept at $10 \mathrm{mM}$. (A) The separation among the doublet for $\mathrm{H}_{g}$ protons of valine in $1(\mathrm{G})$ with increasing amount of host was noted and can be ascribed to partial inclusion of methyl groups in the cavity. (B) $\mathbf{H}_{1}$ protons of the $\gamma-C D(H)$ moiety showed upfield shift with increasing amount of guest. 
(A)

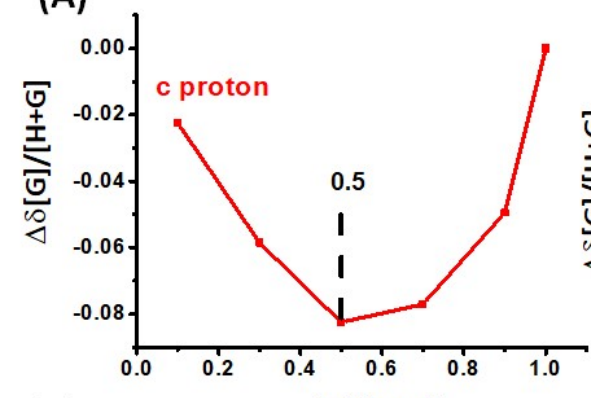

(C)

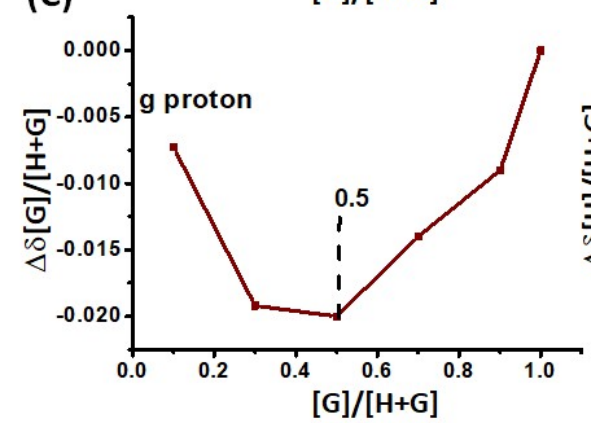

(B)

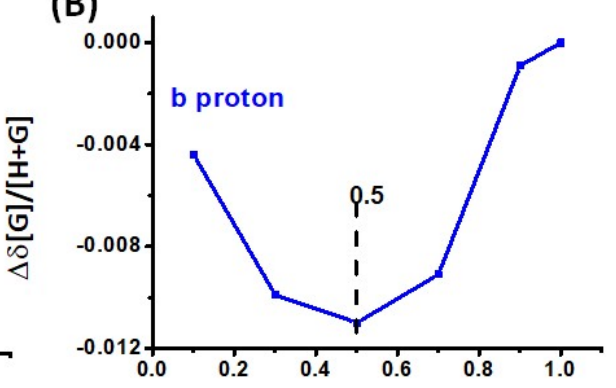

(D)

$[G] /[H+G]$

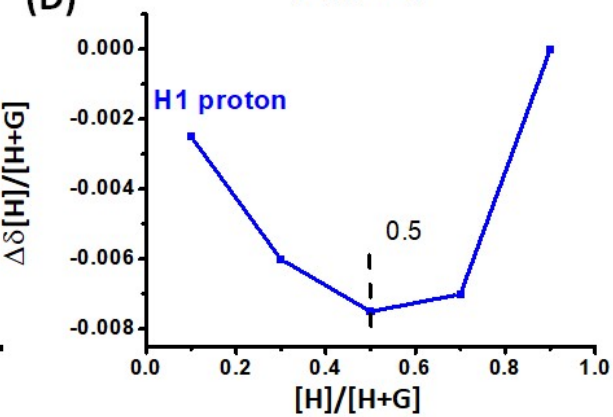

Figure S4: Job's plot obtained by titrating $1(\mathrm{G})$ with $\gamma-\mathrm{CD}(\mathrm{H})$ at different ratio in $\mathrm{D}_{2} \mathrm{O}$ at $25^{\circ} \mathrm{C}$. The changes of chemical shifts of $(A) H_{c}$ protons (B) $\mathrm{H}_{b}$ protons of 4-methylcoumarin moiety (C) $\mathrm{H}_{g}$ protons of valine methyl and (D) $\mathrm{H}_{1}$ ring protons of $\gamma-\mathrm{CD}$ are plotted with the mole fraction of 1 and $\gamma-C D$.

\section{Analysis of structure of $\gamma$-cyclodextrin}

(A)

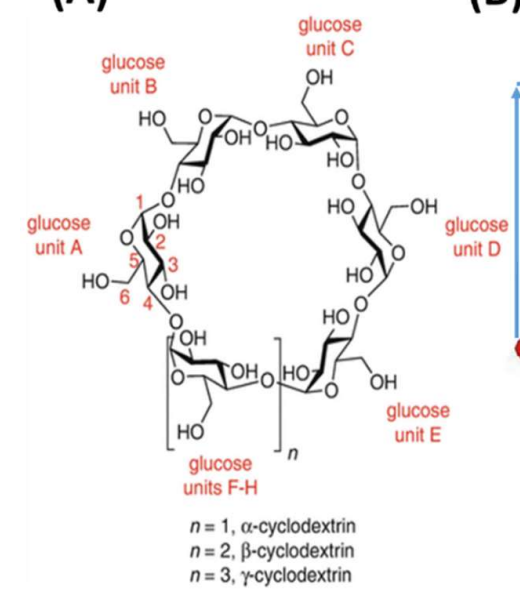

(B)

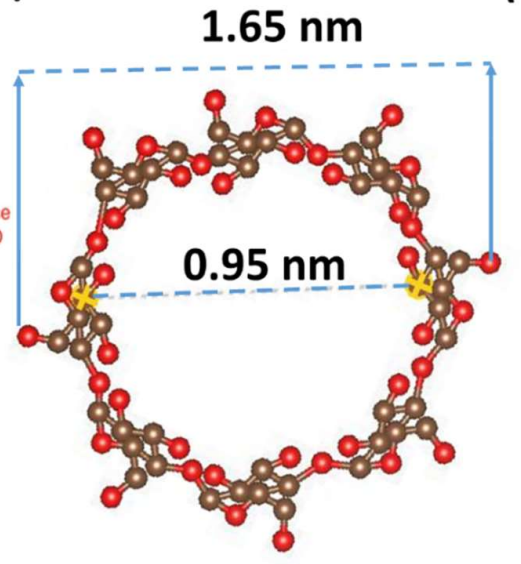

(C)

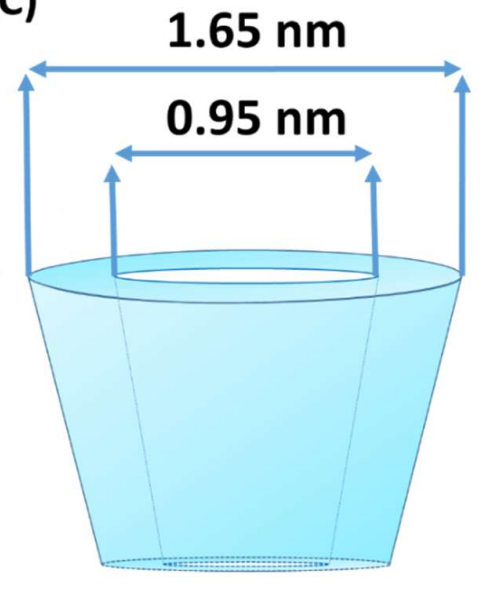

Figure S5: (A) Chemical structure of $\gamma-C D$, (B) ball and stick diagram using Vesta 3 software shows the inner and outer core diameter of $\gamma$-CD. (C) The bucket structure and cavity size of $\gamma$-CD as per literature. ${ }^{2}$ 


\section{Monitoring photodimerization by ${ }^{1} \mathrm{H}$ NMR study.}

Peptide $1(6 \mathrm{mM})$ and an equimolar mixture of 1 and $\gamma-C D$ were dissolved in $0.7 \mathrm{ml} \mathrm{D}_{2} \mathrm{O}$ in different NMR tubes to record ${ }^{1} \mathrm{H}$ NMR. Then both the solutions were irradiated with UV light $(\lambda=320 \mathrm{~nm})$ for 12 hours and again analysed by ${ }^{1} \mathrm{H}$ NMR for the change in integral ratio of $\boldsymbol{a}$ proton with protons $\boldsymbol{c}, \boldsymbol{d}$ $\& \boldsymbol{e}$ while keeping integral proton of $g$ constant. The photodimerization degree (PD) was calculated by the formula, PD $=I_{a} /\left(I_{c}+I_{d, e}\right), \%$ PD $=P D * 100$ where, $I_{a}=$ Integral value of $a$ proton, $I_{c}=$ Integral value of $c$ proton, $I_{d+e}=$ Integral value of $\boldsymbol{d}$ and $\boldsymbol{e}$ proton

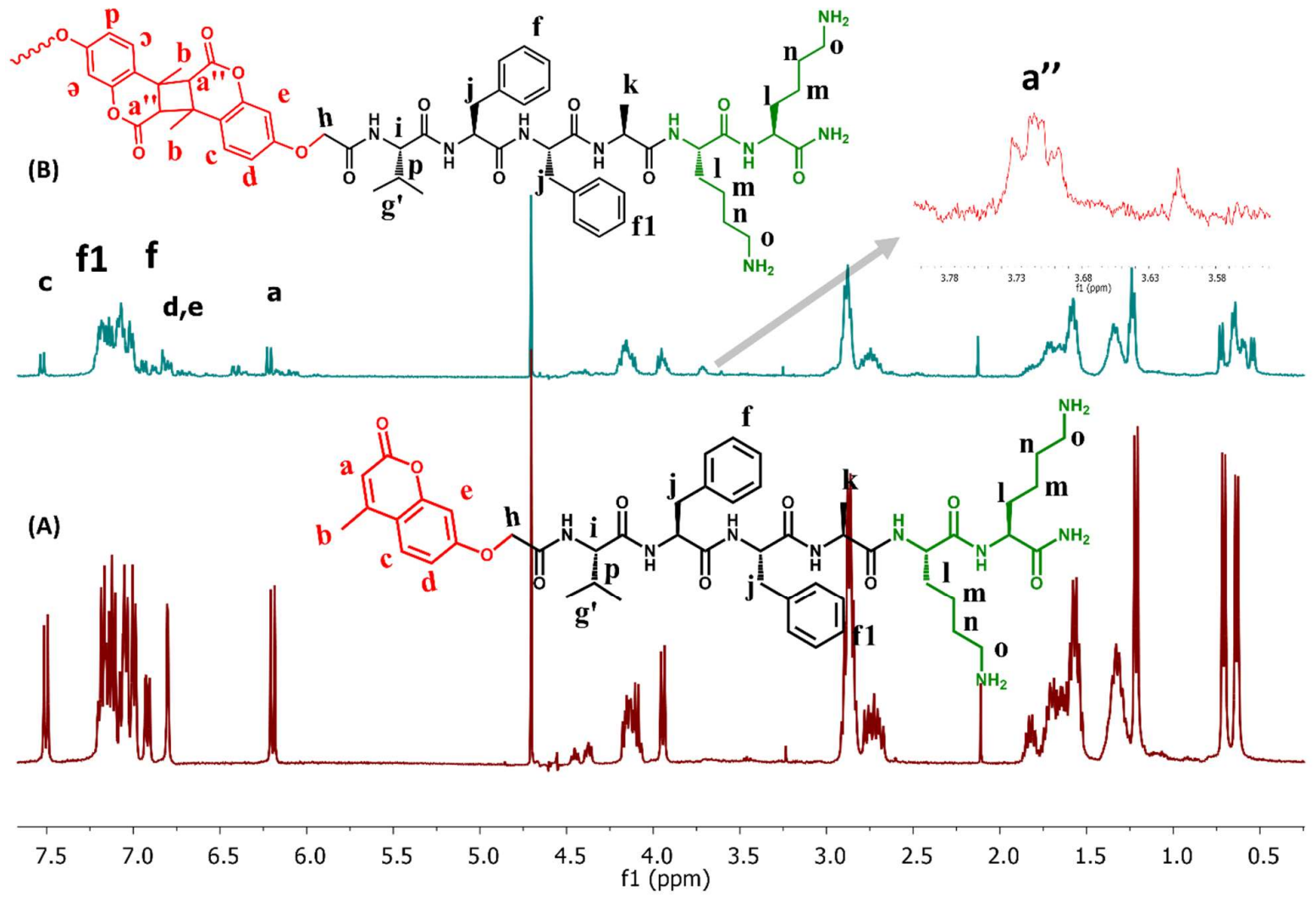

Figure S6: ${ }^{1} \mathrm{H}$ NMR of peptide $1(6 \mathrm{mM})$ in $\mathrm{D}_{2} \mathrm{O}(\mathrm{A})$ before and $(\mathrm{B})$ after irradiation with UV light $(\lambda=$ $320 \mathrm{~nm}$ ) for $12 \mathrm{~h}$ with $16 \mathrm{~W}$ power. The percentage of photodimerization degree was calculated to be $44 \%$. The percentage of photodimerization degree (\%PD) was calculated to be $44 \%$. 


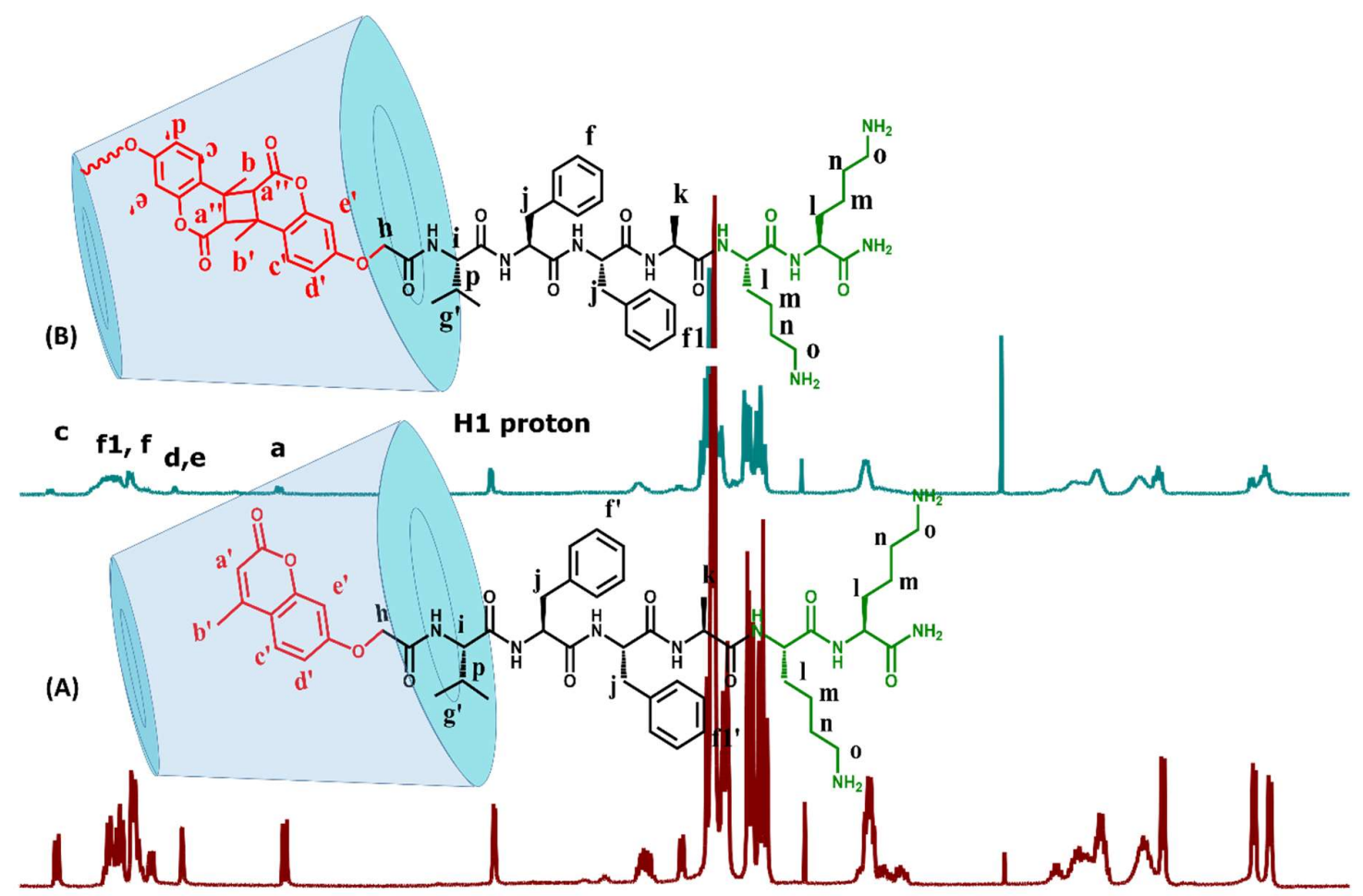

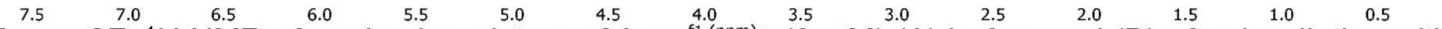

Figure S7: ${ }^{1} \mathrm{H}$ NMR of equimolar mixture of 1 and ${ }^{1}$ (ppeD $(6 \mathrm{mM})(\mathrm{A})$ before and $(B)$ after irradiation with UV light $(\lambda=320 \mathrm{~nm})$ for $12 \mathrm{~h}$ with $16 \mathrm{~W}$ power. The percentage of photodimerization degree (\%PD) was calculated to be $48 \%$.

\section{Monitoring photodimerization by UV spectroscopy}

Peptide 1 ( $0.125 \mathrm{mM})$ and an equimolar mixture of 1 and $\gamma-\mathrm{CD}(0.125 \mathrm{mM})$ in $0.5 \mathrm{~mL}$ water were taken in a UV quartz cuvette. Both the solutions were irradiated with UV light $(\lambda=320 \mathrm{~nm})$ for $4-5 \mathrm{~h}$ and analysed by recording UV spectra at different time intervals to observe for the change in absorbance. Photodimerization degree $(P D)$ was calculated by $P D=\left[\left(\mathbf{A}_{0}-\mathbf{A}_{t}\right) /\left(\mathbf{A}_{0}\right)\right], \% \mathrm{PD}=\mathrm{PD} * 100$ where, $A_{0}=$ Initial Absorbance, $A_{t}=$ Absorbance at time $t$.
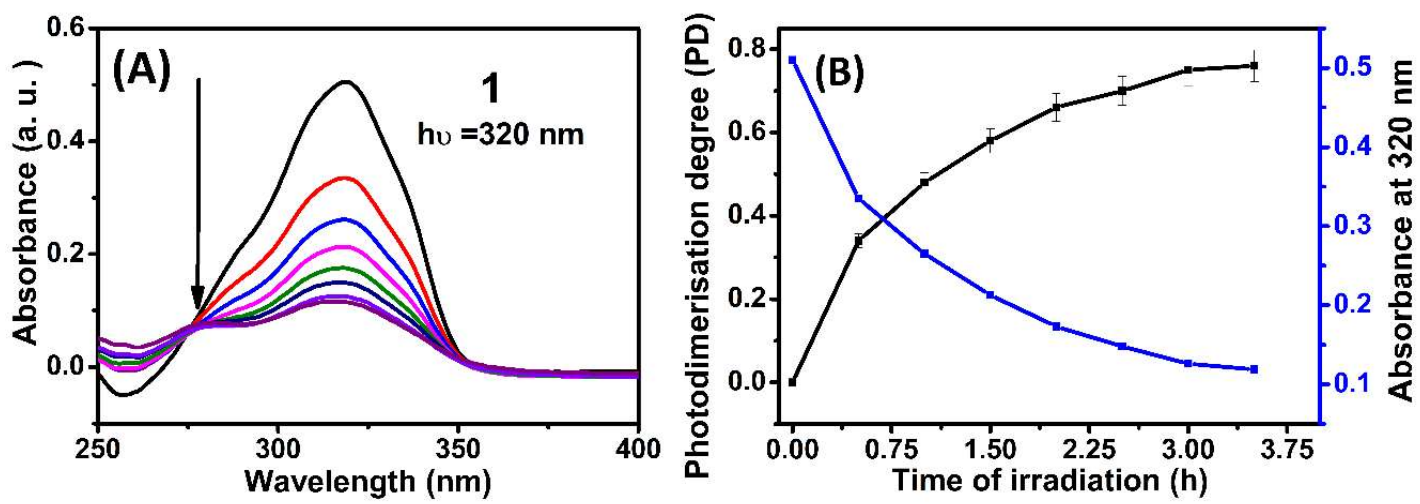

Figure S8: UV spectroscopy data showing photodimerization of $(A) 1(0.1 \mathrm{mM})$ in water (B) corresponding increase in the photodimerization degree (PD) with time of UV irradiation. The percentage of photodimerization degree (\%PD) was calculated to be $74 \%$. 


\section{Multi-step self-assembly of peptide, 1 :}

Nanoparticles and Nanofibers: Peptide, 1 was dissolved in HFIP to form stock solution of $6.25 \mathrm{mM}$ at $10{ }^{\circ} \mathrm{C} .10 \mu \mathrm{L}$ of the stock solution was added to $0.5 \mathrm{ml}$ of water and mixture of HFIP-water in the ratio $1: 3,1: 1$ at $10^{\circ} \mathrm{C}$ to a final concentration of $0.125 \mathrm{mM}$. At this temperature in all the cases, formation of the metastable nanoparticles were observed. The temperature was raised in a controlled manner using stuart waterbath (SWB15D) to $25^{\circ} \mathrm{C}$ to observe transformation into nanofibers.

Nanosheets: $16 \mu \mathrm{L}$ of the stock solution of $1(6.25 \mathrm{mM})$ in HFIP was added to equimolar $\gamma$-CD (0.5 ml) at $10{ }^{\circ} \mathrm{C}$ to a final concentration of $0.2 \mathrm{mM}$. The corresponding solution was kept for UV irradiation ( $\lambda$ $=320 \mathrm{~nm}, 8$ Watts $\times 2$ lamp) for $8 \mathrm{~h}$. Further microscopic analysis was performed to observe formation of 2D nanosheets.

Atomic Force Microscopy (AFM): $15 \mu \mathrm{L}$ of $0.2 \mathrm{mM}$ of the sample solution was drop-casted on Silicon wafer, placed on an ice-waterbath maintained at $10^{\circ} \mathrm{C}$. After 5 minutes, the silicon wafer was washed with $500 \mu \mathrm{L}$ water to remove excess peptide and it was then left to be air-dried in a desiccator. AFM height images were recorded by tapping mode on a Bruker Multimode 8 scanning probe microscope with silicon cantilever (Bruker) and analysed using the software NanoScope Analysis 1.5.
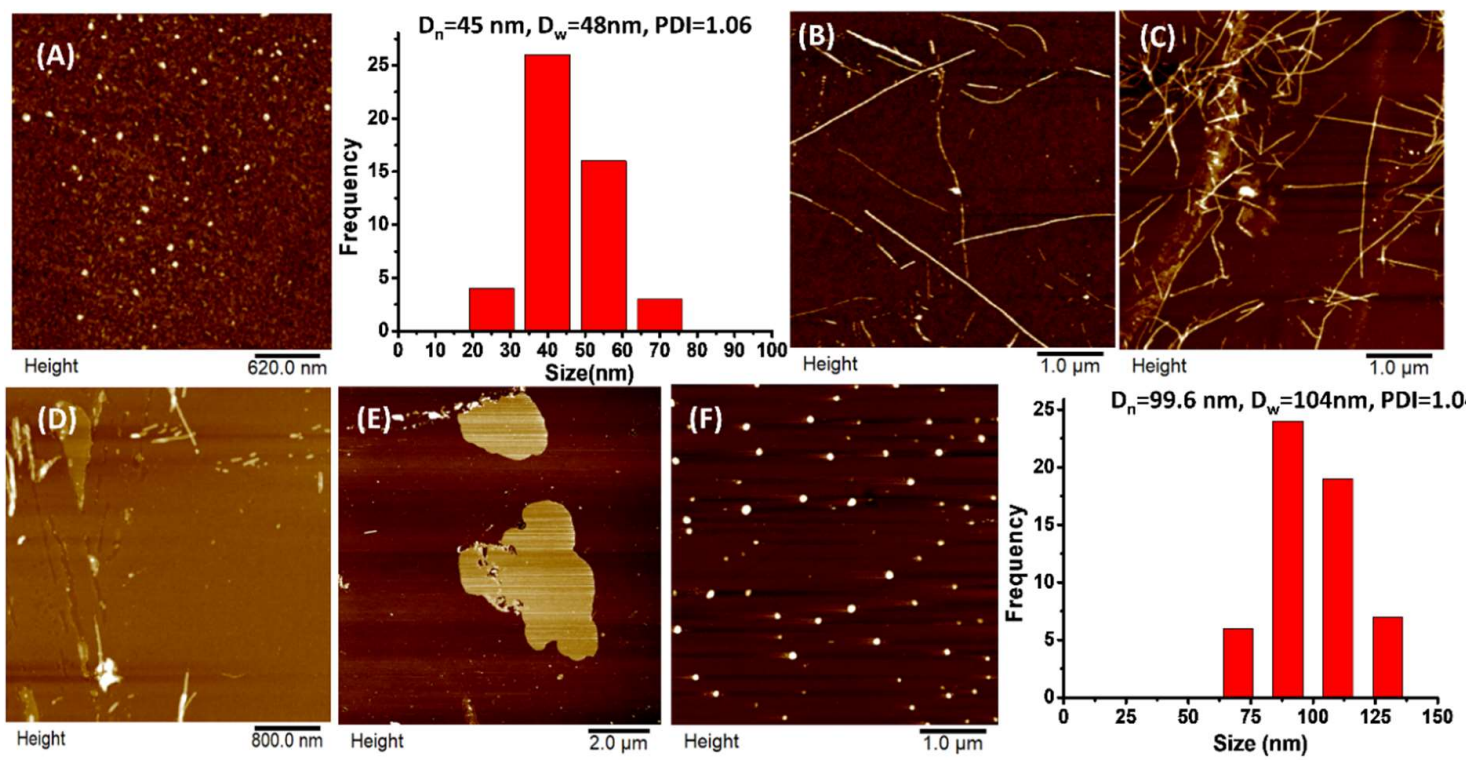

Figure S9: AFM images showing different nanostructures from 1. (A) Metastable nanoparticles, $1_{\mathrm{NP}}$ (height $5-6 \mathrm{~nm}$ ) at $10^{\circ} \mathrm{C}$ obtained by injecting HFIP stock solution of 1 in water $(0.125 \mathrm{mM})$ and corresponding histogram with $D_{n}=45 \mathrm{~nm}, D_{w}=48 \mathrm{~nm}, P D I=1.06,(B)$ nanofibers $1_{\mathrm{NF}}$ (height 6-7 nm) after incubating $1_{\mathrm{NP}}$ solution at $25^{\circ} \mathrm{C}$ for 1 day, $(\mathrm{C})$ covalently fixed nanofibers (di-1) $)_{\mathrm{NF}}$ after UV irradiation $(\lambda$ $=320 \mathrm{~nm}, 8 \mathrm{~h}, 2^{*} 8 \mathrm{~W}$ UV $\mathrm{B}$ lamp), (D) nanofibers $1_{\mathrm{NF}}$ and small nanosheets, $(1 \subset \gamma-\mathrm{CD})_{\mathrm{NS}-\mathrm{NF}}$ from equimolar

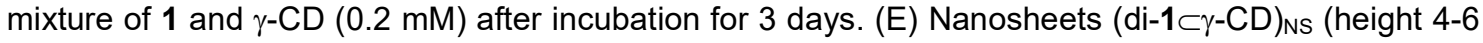
$\mathrm{nm})$ after UV irradiation of $(1 \subset \gamma-C D)_{N S-N F}$ with $\left(\lambda=320 \mathrm{~nm}, 8 \mathrm{~h}, 2^{*} 8 \mathrm{~W} U_{\mathrm{B}}\right.$ lamp). $(\mathrm{F}) \mathrm{UV}$ irradiation of $(\mathrm{di}-1 \subset \gamma-C D)_{N S}$ solution furnished nanoparticles (height 15-25 nm) $\left(\lambda=254 \mathrm{~nm}, 8 \mathrm{~h}, 2^{*} 8 \mathrm{~W} \mathrm{UV}_{\mathrm{C}}\right.$ lamp) with its corresponding histogram showing size analysis, $D_{n}=99.6 \mathrm{~nm}, D_{w}=104 \mathrm{~nm}, \mathrm{PDI}=1.04$. 

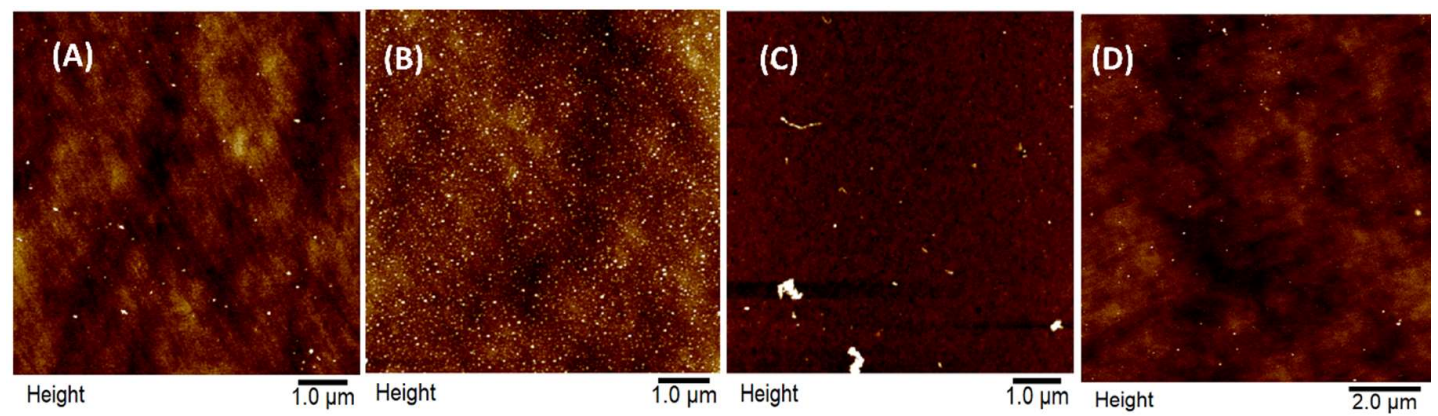

Figure S10: AFM height images of peptide $1(0.125 \mathrm{mM})$ in a mixture of HFIP-Water $(\mathrm{A})$ 1:3 (B) $1: 1$ at $10^{\circ} \mathrm{C}$ after an incubation period of $2 \mathrm{~h}$ and (C) $1: 3$ (D) $1: 1$ at $25^{\circ} \mathrm{C}$ after a incubation period of $5 \mathrm{~h}$.

Transmission Electron Microscopy (TEM): $6 \mu \mathrm{L}$ of sample solution was drop-casted on a 300 mesh carbon-coated copper grid. After $\sim 5$ min, excess solution was blotted using Whatmann filter paper. Extra solution was wicked off by Whatmann filter paper from all edges of the grid carefully. Grids having samples were then dried in the desiccator under vacuum for 1 day. TEM images were recorded using JEOL JEM 2100 with a Tungsten filament at an accelerating voltage of $120 \mathrm{kV}$.
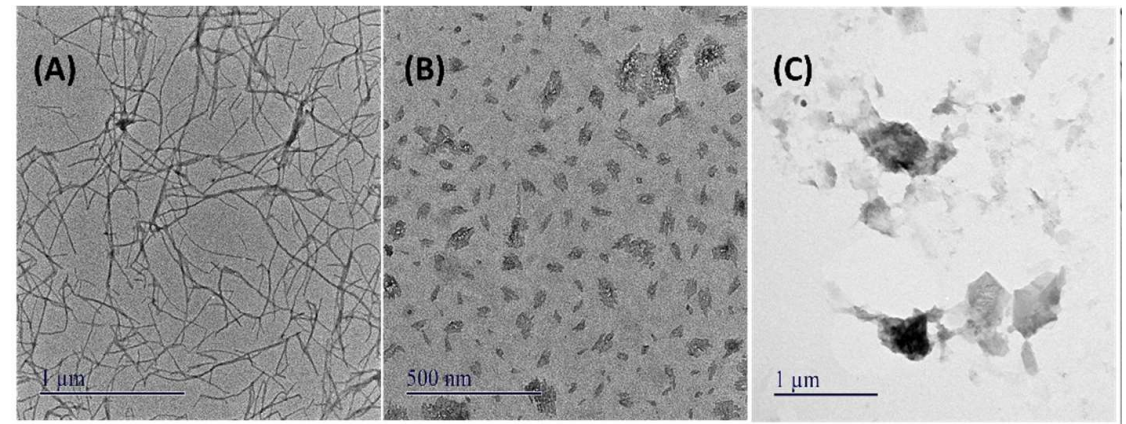

Figure S11: TEM images showing different nanostructures from 1 (A) Nanofibers, $1_{\mathrm{NF}}$ of diameter 7-9 $\mathrm{nm}$ from aqueous solution of $1(0.125 \mathrm{mM})$. Increase in area of $2 \mathrm{D}$ nanosheet $(\mathrm{di}-1 \subset \gamma-C D)_{\mathrm{NS}}$ obtained from equimolar mixture of 1 and $\gamma-C D(0.2 \mathrm{mM})$ with different irradiation time of (B) $2 \mathrm{~h}$ and $(\mathrm{C}) 4 \mathrm{~h}(\lambda=$ $320 \mathrm{~nm}, 2^{*} 8 \mathrm{~W}$ UV $\mathrm{B}$ lamp). 


\section{Thioflavin-T binding and Confocal microscopy images}

ThT undergoes excitation at $440 \mathrm{~nm}$ and gives rise to emission band at $480-500 \mathrm{~nm}$ only when it is bound to an ordered secondary structures of protein, peptides. $2 \mu \mathrm{L}$ of ThT solution ( $2 \mathrm{mM}$ DMF stock) was added to $400 \mu \mathrm{L}$ of sample solution in eppendorf tube. After 2 minutes of vortexing and incubation for $5 \mathrm{~min}$, fluorescence emission spectra were recorded. One dimensional ordered supramolecular nanofibers, 2D nanosheet showed much higher emission intensity as compared to THT in water.

For obtaining the confocal fluorescence images of the Thioflavin-T (ThT) stained nanostructures, the confocal laser scanning microscope LSM 880 (Carl Zeiss) equipped with a confocal detector was used. The solution $(0.2 \mathrm{mM}, 30 \mu \mathrm{l})$ was spotted on a glass slide and covered with cover slip and kept at room temperature overnight for drying. An objective lens with a 100x magnification and the fixed laser line $488 \mathrm{~nm}$ was used for excitation.
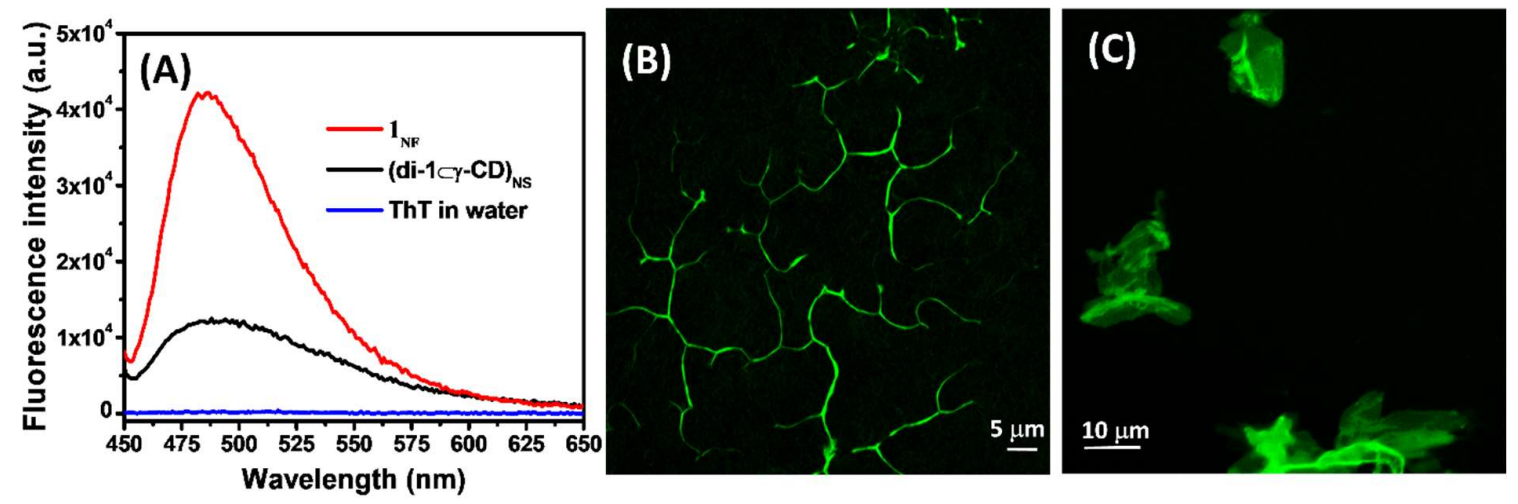

Figure S12: (A) Fluoresence emission spectra as a consequence of ThT binding to the 1D nanofiber $1_{\mathrm{NF}}$ from aqueous solution of peptide $1(0.5 \mathrm{mM})$ and $2 \mathrm{D}$ nanosheet $(\mathrm{di}-1 \subset \gamma-\mathrm{CD})_{\mathrm{NS}}$ from equimolar solution of 1 with $\gamma$-CD $(0.5 \mathrm{mM})$. Control experiment was performed by adding ThT in water. ThT stained confocal microscopy images of $(B)$ nanofibers from 1 and $(C)$ nanosheets from equimolar mixture of 1 and $\gamma-C D(0.2 \mathrm{mM})$ after $8 \mathrm{~h}$ of irradiation with UV light at $320 \mathrm{~nm}\left(2^{*} 8 \mathrm{~W} U V_{B}\right.$ lamp). 


\section{FT-IR studies}

The peaks at $1626 \mathrm{~cm}^{-1}$ (amide I) and $1548 \mathrm{~cm}^{-1}$ (amide II) indicate the existence of parallel 6 -sheet. The strong absorbance at $3274 \mathrm{~cm}^{-1}, 3060 \mathrm{~cm}^{-1}$ and $2935 \mathrm{~cm}^{-1}$ correspond to the $\mathrm{N}-\mathrm{H}$ stretching, $-\mathrm{CH}_{3} /-$ $\mathrm{CH}_{2}$ anti-symmetric and symmetric stretching, respectively. The peak associated with $1670 \mathrm{~cm}^{-1}$ is due to bound TFA counterions. ${ }^{3}$

(A)

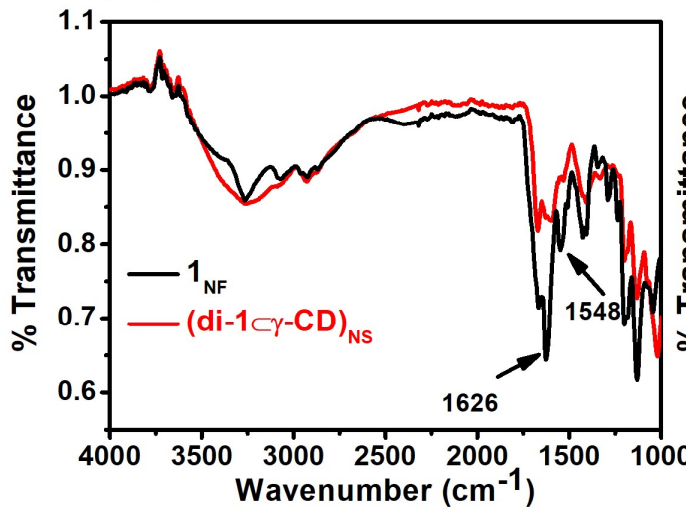

(B)

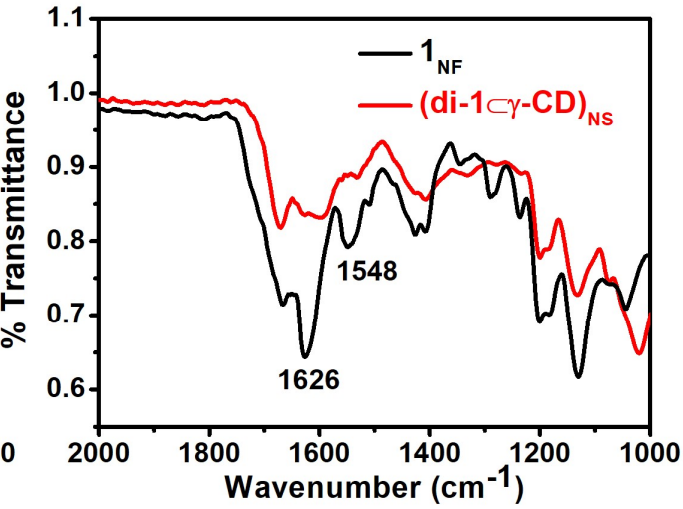

Figure S13: (A) Full and (B) Magnified FTIR spectra of freeze-dried sample of $\mathbf{1}_{\mathrm{NF}}$ and $(\mathrm{di}-1 \subset \mathrm{c}-\mathrm{CD})_{\mathrm{NS}}$ at $25^{\circ} \mathrm{C}$ (concentration $\left.=10 \mathrm{mM}\right)$.

\section{X-Ray Diffraction studies}

The XRD pattern of the fibers and sheets $(10 \mathrm{mM})$ were recorded on Bruker X-ray diffractometer at a range of $2^{\circ}-40^{\circ} .1_{\mathrm{NF}}$ and $(\mathrm{di}-1 \subset \gamma \mathrm{CD})_{\mathrm{NS}}(10 \mathrm{mM})$ solution was drop-casted on glass substrate separately and kept for drying overnight and analysed by XRD. Both the fibers and sheets showed peaks, albeit sharper for the fibers. The peaks at $2 \theta=20,30$ corresponding to $d=0.43$ and $0.32 \mathrm{~nm}$ account for the $\beta$-sheet distance between amides and $\pi-\pi$ distance between aromatic amino acids residues for $\mathbf{1}_{\mathrm{NF}}$. For $(\mathrm{di}-\mathbf{1} \subset \gamma \mathrm{CD})_{\mathrm{NS}}$ there was a minor variation in the $\beta$-sheet distance $d=0.46 \mathrm{~nm}$.

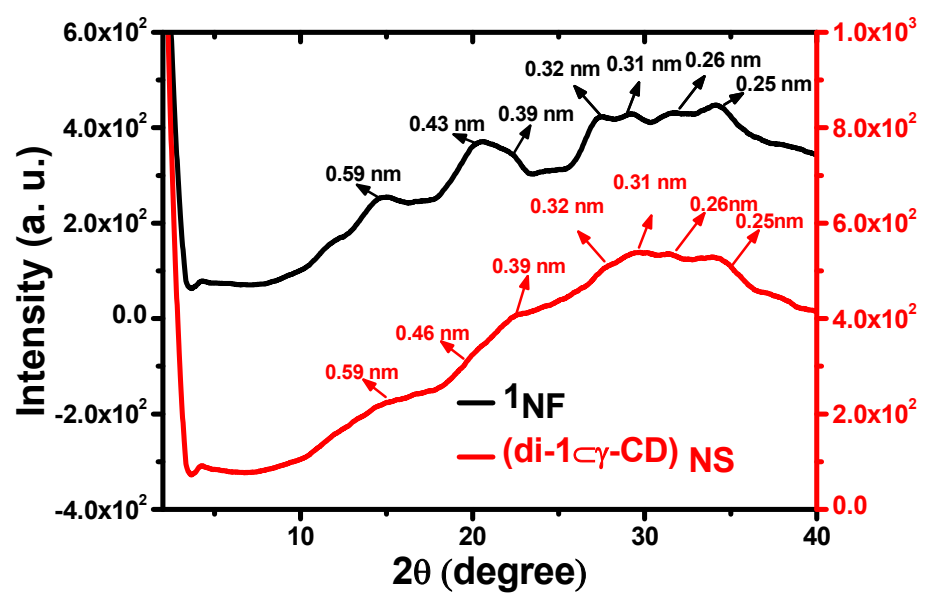

Figure S14: XRD spectrum showing characteristic peaks of both peptide $\mathbf{1}_{\mathrm{NF}}$ and $(\mathrm{di}-\mathbf{1} \subset \gamma-\mathrm{CD})_{\mathrm{NS}}$ solutions $(10 \mathrm{mM})$. 


\section{Generation of seeds by mechanical stirring}

a) Generation of fibre seeds by probe sonication: $500 \mu \mathrm{L}$ of pre-assembled $\mathbf{1}_{\mathrm{NF}}$ solution $(0.2 \mathrm{mM})$ was taken in $2 \mathrm{ml}$ eppendorf which was fixed with a stand in a glass beaker having ice cold water. Then probe microtip (4417 number) was dipped into the sample and was sonicated using QSonica (model number Q700, power 700 watts and frequency $20 \mathrm{kHz}$ ) at an amplitude of $20 \%$ for $\sim 10$ minutes (5 sec on and 5 sec off to avoid heating due to the probe).

b) Generation of sheet seeds by mechanical stirring: $500 \mu \mathrm{L}$ of sheet solution $(\mathrm{di}-1 \subset \gamma-\mathrm{CD})_{\mathrm{NS}}(0.2 \mathrm{mM})$ was taken in $2 \mathrm{ml}$ eppendorf and was kept on stirring at $600 \mathrm{rpm}$ for $6 \mathrm{~h}$ using IKA magnetic stirrer. The formation of the short seeds were monitored by recording the AFM of the samples.

Analysis of average length (fibers) and area (sheets) from AFM images: AFM images were recorded for the short seeds and growing fibers, sheets as obtained from different ratio of seeds and monomers. The length distributions of the fibers were analyzed using image-J software, from the U.S. National Institutes of Health. 100 random fibers and 50 sheets each were selected from different areas of the images and a histogram was generated by choosing bin and frequency in Microsoft Excel. The average lengths, areas and PDI were estimated by calculating number average length, Area $\left(L_{n}, A_{n}\right)$ and weight average fiber length, area $\left(L_{w}, A_{w}\right)$ and the ratio $L_{w} / L_{n}, A_{w} / A_{n}$ using eqn. 1-3, where $N_{i}$ is the number of fibers and sheets of length $L_{i}$ and area $A_{i}$, respectively and $n$ is the number of fibers and sheets examined in each sample.

$$
\begin{aligned}
& \mathrm{L}_{\mathrm{w}}=\frac{\sum_{i=1}^{n} N_{i} L_{i}{ }^{2}}{\sum_{i=1}^{n} N_{i} L_{i}}, A_{\mathrm{w}}=\frac{\sum_{i=1}^{n} N_{i} A_{i}{ }^{2}}{\sum_{i=1}^{n} N_{i} A_{i}} \\
& \mathrm{~L}_{n}=\frac{\sum_{i=1}^{n} N_{i} L_{i}}{\sum_{i=1}^{n} N_{i}} \quad A_{n}=\frac{\sum_{i=1}^{n} N_{i} A_{i}}{\sum_{i=1}^{n} N_{i}} \\
& P D I=\mathrm{L}_{\mathrm{w}} / \mathrm{L}_{\mathrm{n}}
\end{aligned}
$$



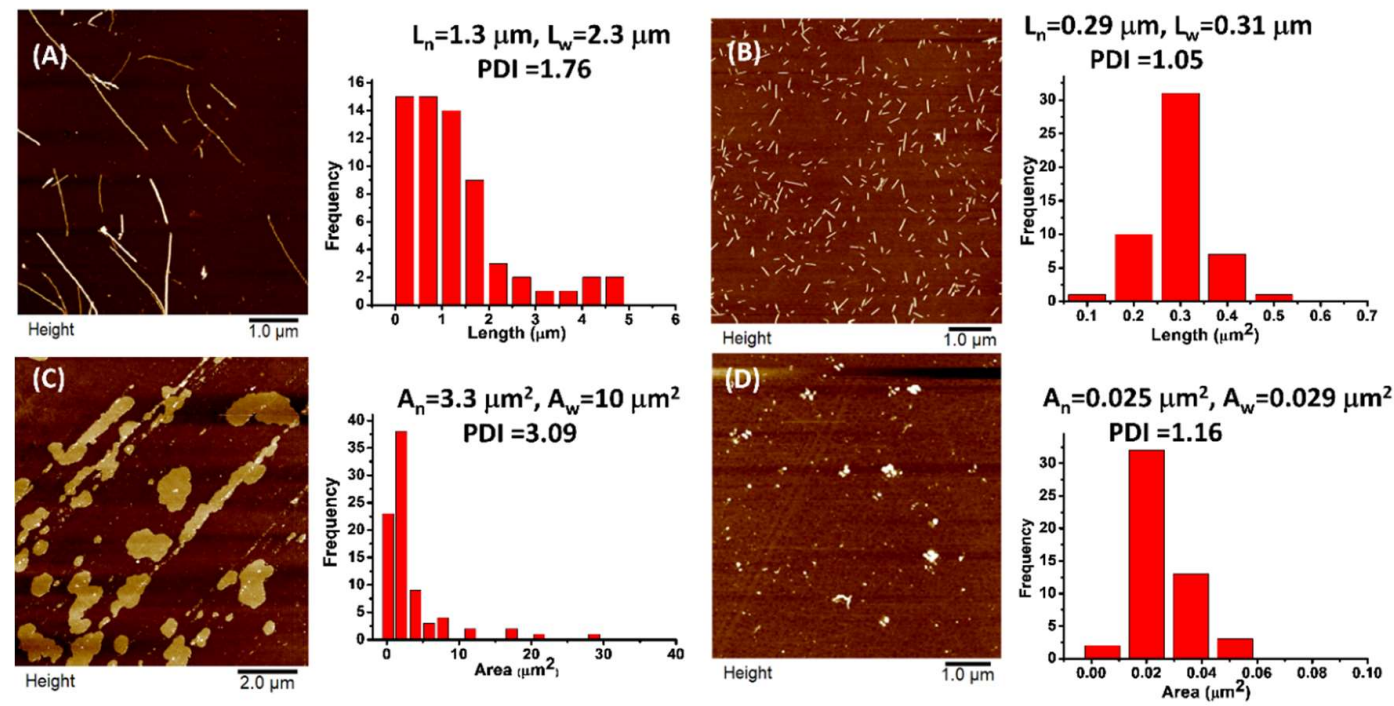

Figure S15: AFM images and corresponding histogram analysis showing generation of short seeds of $1_{\mathrm{NF}}$ and $(\mathrm{di}-1 \subset \gamma-\mathrm{CD})_{\mathrm{NS}}$. (A) Polydisperse $1_{\mathrm{NF}}(0.2 \mathrm{mM})\left(L_{\mathrm{n}}=1285 \mathrm{~nm}, \mathrm{PDI}=1.76\right)$, (B) generation of short fiber seeds by probe sonication to result seeds with $L_{n}=294 \mathrm{~nm}, \mathrm{PDI}=1.05$, (C) Nanosheets of $(\text { di-1 } \subset Y-C D)_{N S}$ irradiated at $320 \mathrm{~nm}$ for $8 \mathrm{~h}\left(8\right.$ Watts $^{*} 2 \mathrm{UV}_{B}$ lamp $)\left(A_{n}=3.3 \mu \mathrm{m}^{2}, \mathrm{PDI}=3.09\right)(\mathrm{D})$ generation of short seeds with small area and narrow PDI $\left(A_{n}=0.025 \mu \mathrm{m}^{2}, \mathrm{PDI}=1.16\right)$ by mechanical stirring at $1000 \mathrm{rpm}$ for 1 day.

\section{Seeded Supramolecular Polymerization:}

Seeded supramolecular polymerization (SSP) was performed taking different ratio of the nanofiber $\left(\mathbf{1}_{\mathrm{NF}}\right)$ seeds and metastable nanoparticles $\left(\mathbf{1}_{\mathrm{NP}}\right)$ (Table S1) at $15{ }^{\circ} \mathrm{C}$ to furnish different length distribution of the fibers. In absence of the monomer $\left(\mathbf{1}_{\mathrm{NP}}\right)$, the length distribution of the seeds remains unchanged even after 4 days. In a separate experiment, seeds of $2 D$ nanosheet, $(\text { di-1 } 1 \subset \gamma-C D)_{N S}$ were added in different ratio to equimolar mixture of monomers $\left(\mathbf{1}_{\mathrm{NP}}\right)$ with $\gamma-\mathrm{CD}$ at $15^{\circ} \mathrm{C}$ in order to furnish sheets with growing area distribution.

Table S1: Different ratios of seed and nanoparticles of 1 taken for seeded supramolecular polymerization

\begin{tabular}{|c|c|c|c|c|}
\hline S No & $\begin{array}{c}\text { Fibre seeds } \\
\text { Seed : } 1_{\mathrm{NP}}\end{array}$ & $\begin{array}{l}\text { Volume of Fibre } \\
\text { seed solution }\end{array}$ & $\begin{array}{c}\text { Volume of monomer } \\
\left(1_{\mathrm{NP}}\right)\end{array}$ & $\begin{array}{l}\text { Total } \\
\text { volume }\end{array}$ \\
\hline 1 & 1:9 & $10 \mu \mathrm{L}$ & $90 \mu \mathrm{L}$ & $100 \mu \mathrm{L}$ \\
\hline 2 & $1: 2.34$ & $30 \mu \mathrm{L}$ & $70 \mu \mathrm{L}$ & $100 \mu \mathrm{L}$ \\
\hline \multirow[t]{3}{*}{3} & 1: 1 & $50 \mu \mathrm{L}$ & $50 \mu \mathrm{L}$ & $100 \mu \mathrm{L}$ \\
\hline & Fibre seeds & \multirow{2}{*}{$\begin{array}{l}\text { Volume of sheet } \\
\text { seed solution }\end{array}$} & \multirow{2}{*}{$\begin{array}{l}\text { Volume of equimolar } \\
\text { monomer }\left(1_{N P}\right)+\gamma C D\end{array}$} & \\
\hline & Seed : $1_{\mathrm{NP}}+\gamma-\mathrm{CD}$ & & & \\
\hline 1 & 1: 9 & $10 \mu \mathrm{L}$ & $90 \mu \mathrm{L}$ & $100 \mu \mathrm{L}$ \\
\hline 2 & 1: 2.34 & $30 \mu \mathrm{L}$ & $70 \mu \mathrm{L}$ & $100 \mu \mathrm{L}$ \\
\hline 3 & 1: 1 & $50 \mu \mathrm{L}$ & $50 \mu \mathrm{L}$ & $100 \mu \mathrm{L}$ \\
\hline
\end{tabular}




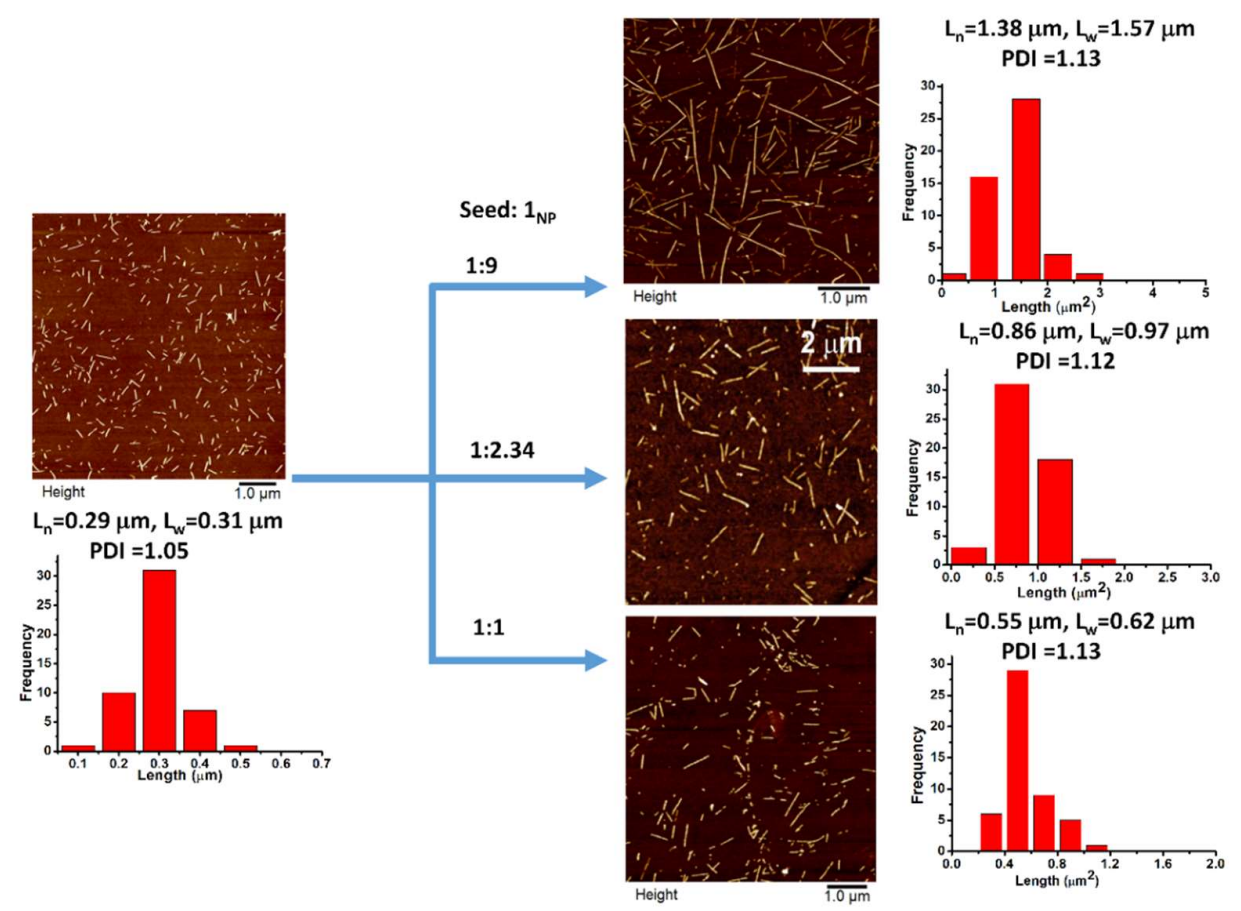

Figure S16: AFM images and corresponding histograms showing seeded supramolecular polymerization using different ratios of $1_{\mathrm{NF}}$ seed and monomer $1_{\mathrm{NP}}$ incubated at $15{ }^{\circ} \mathrm{C}$ for $8 \mathrm{~h}$ to get different length distributions of fibers with excellent control over PDI values.
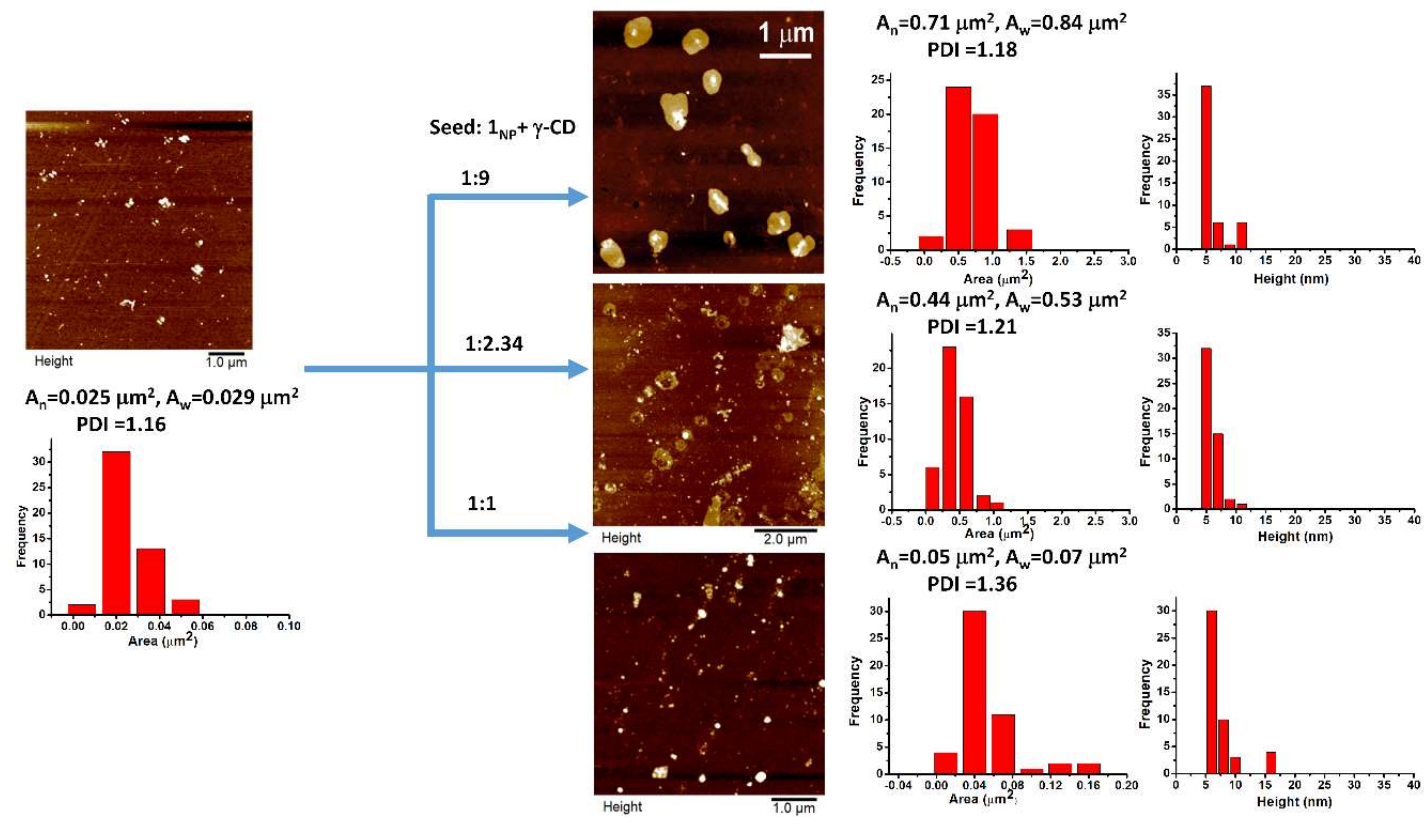

Figure S17: AFM images and corresponding histograms showing seeded supramolecular polymerization using different ratios of $(\mathrm{di}-\mathbf{1} \subset \gamma-\mathrm{CD})_{\mathrm{NS}}$ seed and monomer $\mathbf{1}_{\mathrm{NP}}+\gamma-\mathrm{CD}$ incubated at 15 ${ }^{\circ} \mathrm{C}$ for 1 day to get different area distributions of the sheets. Histograms for height show retention of sheet height $(5 \mathrm{~nm})$ generated from SSP, suggesting 2-dimensional growth of the peptide sheets. 
Cross-seeding experiments were performed incubating 1:1 ratio of the nanofiber $\left(\mathbf{1}_{\mathrm{NF}}\right)$ seeds and a mixture of metastable nanoparticles $\left(\mathbf{1}_{\mathrm{NP}}\right)$ and $\gamma-\mathrm{CD}$ at $15^{\circ} \mathrm{C}$ for 1 day. In one case the solution were irradiated $(\lambda=320 \mathrm{~nm})$ for $9 \mathrm{~h}$ during incubation period. In absence of UV irradiation, the $\mathbf{1}_{\mathrm{NF}}$ seed promoted fiber growth with slight increase in PDI values. This suggests competition of the hydrogen bonding interaction among the peptide units and host-guest interaction between $\mathbf{1}_{\mathrm{NP}}$ and $\gamma-\mathrm{CD}$, albeit hydrogen bonding interaction dominating over host-guest interaction. However, UV irradiation and subsequent formation of strong pseudo-rotaxane complex e.g. (di-1 $\subset \gamma-C D)_{N S}$ enhanced the stability of host-guest interaction and resulted in mixed population of $\mathbf{1}_{\mathrm{NF}}$ fiber seed and polydisperse nanosheets $(\mathrm{di}-1 \subset \gamma-\mathrm{CD})_{\mathrm{NS}}$.

In a separate cross-seeding experiment, seeds of 2D nanosheet, $(\mathrm{di}-1 \subset \mathrm{C}-\mathrm{CD})_{\mathrm{NS}}$ were added to monomers $\left(\mathbf{1}_{\mathrm{NP}}\right)$ in $1: 1$ ratio at $15{ }^{\circ} \mathrm{C}$ and were incubated for 1 day (Figure S18). Formation of uncontrolled $\mathbf{1}_{\mathrm{NF}}$ fibers from $\mathbf{1}_{\mathrm{NP}}$ was observed $(\mathrm{PDI}=1.33)$ while dimension of $(\mathrm{di}-\mathbf{1} \subset \gamma-\mathrm{CD})_{\mathrm{NS}}$ seeds of the nanosheets remained unchanged
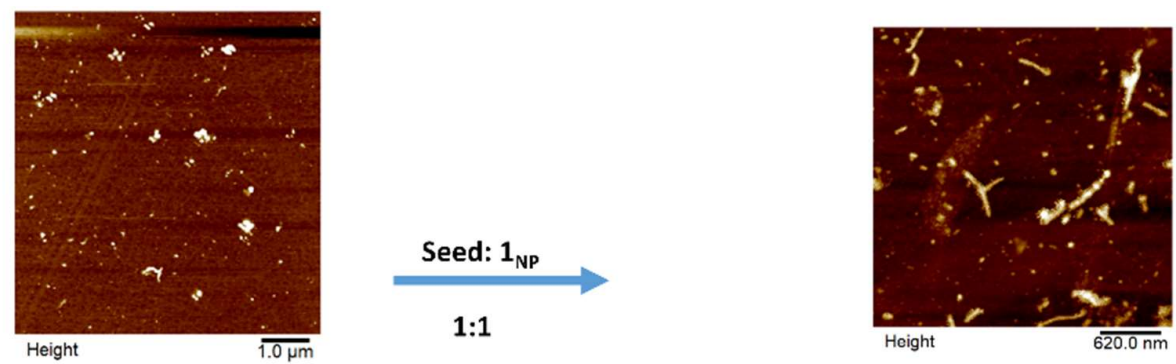

$A_{n}=0.025 \mu m^{2}, A_{w}=0.029 \mu m^{2}$
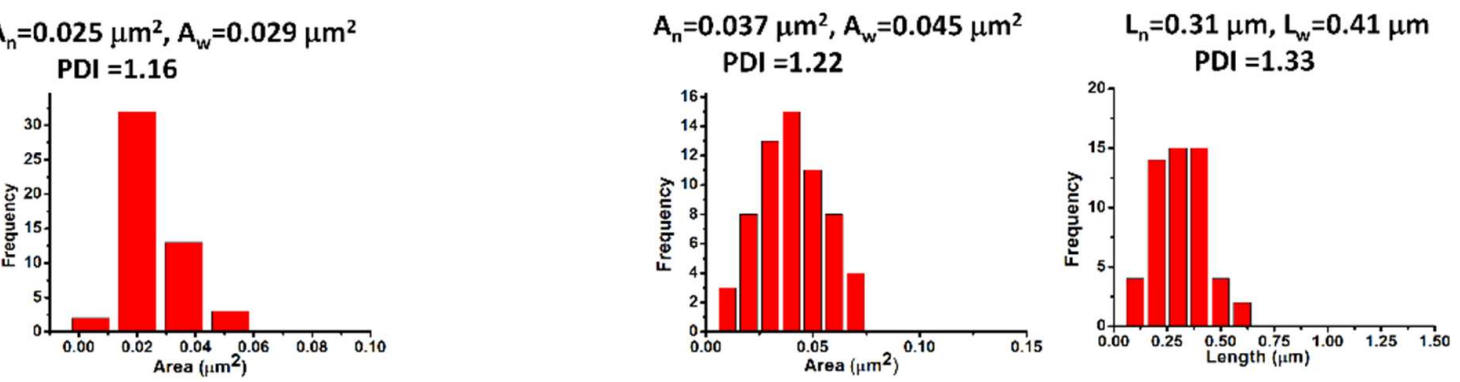

Figure S18: Cross-seeding experiment with incubating $(\mathrm{di}-1 \subset \gamma-C D)_{\mathrm{NS}}$ seed and monomer $\mathbf{1}_{\mathrm{NP}}$ in $1: 1$ ratio at $15{ }^{\circ} \mathrm{C}$ for 1 day. The AFM images and histogram analyses suggest formation of uncontrolled $\mathbf{1}_{\mathrm{NF}}$ fibers from $\mathbf{1}_{\mathrm{NP}}$ and $(\mathrm{di}-\mathbf{1} \subset \gamma-\mathrm{CD})_{\mathrm{NS}}$ seeds of the nanosheets remained unchanged. 


\section{Hydrogel Formation \& Rheological study:}

The $\mathbf{1}_{\mathrm{NF}}$ and $(\mathrm{di}-\mathbf{1} \subset \gamma-\mathrm{CD})_{\mathrm{Ns}}$ solutions of concentration $8.46 \mathrm{mM}$ (1 wt\%) were prepared in sodium phosphate buffer (SPB) (10 mM at pH 7). These phosphate counter anions in the sodium phosphate buffer entangled the positively charged peptide nanofibers to form a network structure (Figure S19) resulting in the formation of hydrogel. Similarly, the height of the $2 \mathrm{D}$ nanosheets, (di-1 $\subset \gamma-C D)_{N S}$ also increased with upon interaction with the phosphate ions.
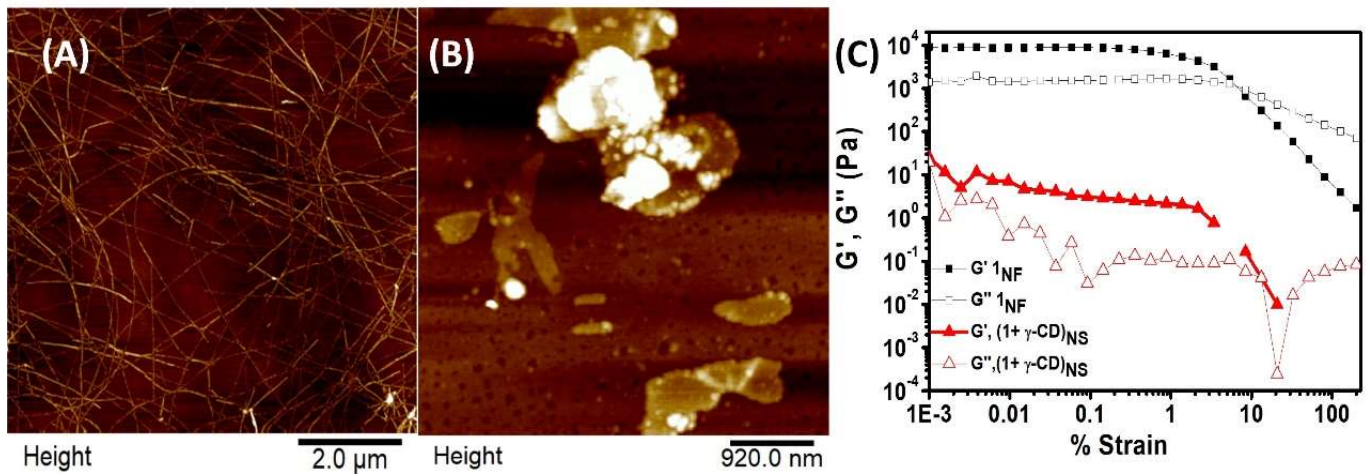

Figure S19: AFM image of the (A) hydrogel $1_{\mathrm{NF}}$ from $1 \mathrm{wt} \%(8.46 \mathrm{mM})$ gel of 1 in sodium phosphate

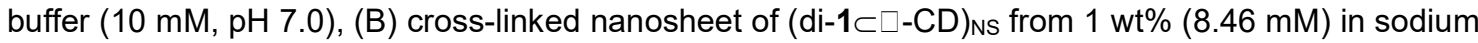
phosphate (10 mM, pH 7.0) buffer. (C) Storage modulus (G') and Loss modulus (G") of the amplitude sweep oscillatory rheology for the $\mathbf{1}_{\mathrm{NF}}$ hydrogel and $(\mathrm{di}-1 \subset \gamma-\mathrm{CD})_{\mathrm{NS}}$ solution in buffer $(8.46 \mathrm{mM}, \mathrm{pH} 7.0)$.

For rheological characterization of the hydrogel, Rheoplus 302 device using a cone and plate (CP-252) geometry with an adjustable peltier temperature controlling system was utilized. An oscillatory stress amplitude sweep experiment was performed at a constant angular frequency of $10 \mathrm{rad} / \mathrm{s}$ for the strain range $0.01-100$ at $25^{\circ} \mathrm{C}$ to discern the linear viscoelastic region at measuring distance of 0.2 $\mathrm{mm}$. The $\mathrm{G}^{\prime}, \mathrm{G}^{\prime \prime}$ and yield stress values from the hydrogel of $\mathbf{1}_{\mathrm{NF}}$ showed much higher values as compared to that from (di-1 $\subset \gamma-C D)_{N S}$ (Figure S19C).

Oscillatory frequency sweep experiments were performed in the linear viscoelastic region with a constant strain of $0.1 \%$ to ensure that calculated parameters correspond to an intact network structure. The software converted the torque measurements into either $\mathrm{G}^{\prime}$ (the storage modulus) and $\mathrm{G}^{\prime \prime}$ (the loss modulus). Thixotropic studies for the hydrogel from $\mathbf{1}_{\mathrm{NF}}$ in $10 \mathrm{mM} \mathrm{SPB}$ was measured using parallel plate at a constant value for angular frequency $(10 \mathrm{rad} / \mathrm{s})$ and strain $(0.1 \%)$ at $25^{\circ} \mathrm{C}$. Data points were plotted between storage $\left(G^{\prime}\right)$, loss $\left(G^{\prime \prime}\right)$ moduli and time. The gel network was completely broken at $100 \%$ strain, however, it regains its gelation ability when the strain value was set back to 0.1 $\%$. Three consecutive cycles were performed with change in strain of $0.1-100-0.1-100-0.1 \%$ with a constant angular frequency of $10 \mathrm{rad} / \mathrm{s}$. 


\section{3. $\mathrm{MoS}_{2}$ Exfoliation study:}

Stock dispersions were prepared by adding bulk $\operatorname{MoS}_{2}(0.16 \mathrm{mg})$ in powder form to $0.25 \mathrm{ml}$ solutions of $\mathbf{1}_{\mathrm{NF}}$ as well as (di-1 $\left.\subset \gamma-C D\right)_{\mathrm{NS}}(2 \mathrm{mM}$ each). Afterwards the dispersions were stirred overnight at $\sim 250$ $\mathrm{rpm}$. The dispersions were characterized by UV-vis spectroscopy at $0.1 \mathrm{mM}$. It gives the characteristics peaks of exfoliated $\mathrm{MoS}_{2}$ at $615 \mathrm{~nm}$ and $679 \mathrm{~nm}$. A little higher absorbance values for the exfoliated $\mathrm{MoS}_{2}$ peaks for $\mathbf{1}_{\mathrm{NF}}$ which could be attributed to the more exposed amphiphilic character compared to the $(\mathrm{di}-\mathbf{1} \subset \mathrm{C}-\mathrm{CD})_{\mathrm{NS}}$. Also, the dispersions of $\mathrm{MoS}_{2}$ in $\mathbf{1}_{\mathrm{NF}}$ is quite stable for ca. 1 month, while the

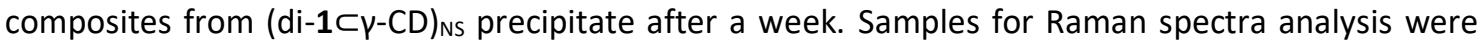
prepared by dropcasting $10 \mu \mathrm{L}$ of stock solution on silicon wafer. Raman spectra provide characteristic information for the thickness of layers. Raman spectra provides strong signals for the two Raman active modes $\mathrm{E}_{2 \mathrm{~g}}^{1}$ and $\mathrm{A}_{1 \mathrm{~g}}$ confirming the presence of exfoliated $\mathrm{MoS}_{2}$ for both $\mathbf{1}_{\mathrm{NF}}$ and $(\mathrm{di}-\mathbf{1} \subset \mathrm{\gamma}-\mathrm{CD})_{\mathrm{NS}}$ solution vibrational Raman active modes. The signal for exfoliated $\mathrm{MoS}_{2}$ using nanofibers are sharper than that from nanosheet.

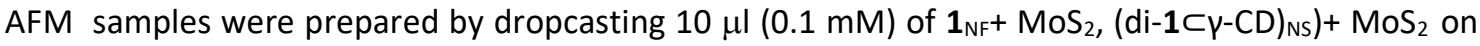
silicon wafer and dried overnight in desiccator. Height of the short nanofiber and exfoliated $\mathrm{MoS}_{2}$ sheet is 6-7 $\mathrm{nm}$ and 1-2 $\mathrm{nm}$ (mono- and bilayer) respectively. The formation of short fibers is attributed with the breaking of long polydispersed fibers which rendered the exfoliation of bulk MoS 2 imparting green color to the solution. TEM samples were prepared by dropcasting $6 \mu \mathrm{l}(0.1 \mathrm{mM})$ of $\mathbf{1}_{\mathrm{NF}}+\mathrm{MoS}_{2}$, $\left(\right.$ di-1 $\left.1 \subset-(C D)_{N S}\right)+M_{2}$ on 300 mesh carbon coated copper grid. Figure S20B shows layer by layer

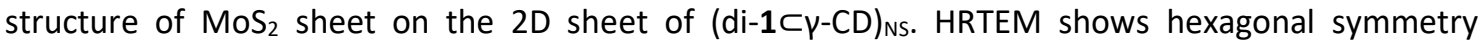
confirming undistorted lattice of pristine $\mathrm{MoS}_{2}$ single or bilayers.
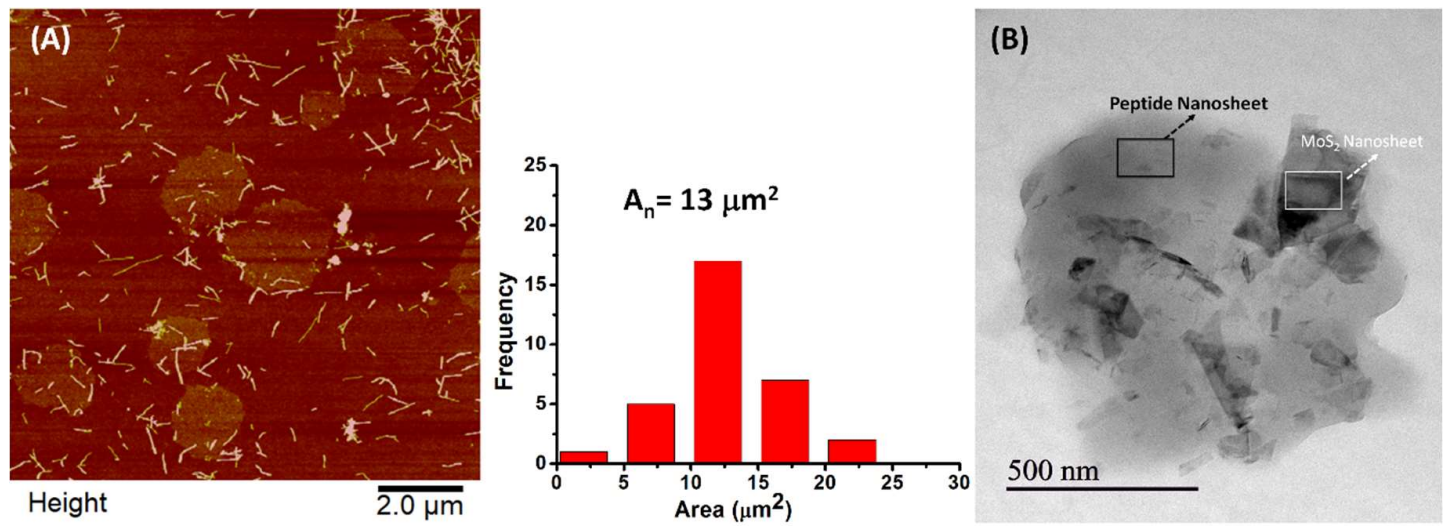

Figure S20: (A) AFM image showing $\mathrm{MoS}_{2}$ nanosheets exfoliated in different areas of $\mathbf{1}_{\mathrm{NF}}$ solution $(0.25$ $\mathrm{mM}$ ) with its corresponding histogram shows $A_{n}=13 \mu \mathrm{m}^{2}$, (B) TEM image showing exfoliated $\mathrm{MoS}_{2}$ with peptide nanosheets, 


\section{References}

1. Huyck, R. H.; Trenor, S. R.; Love, B. J.; Long, T. E. J. Macromol. Sci. Part A, 2007, 45, 9-15.

2. Szejtli, J. Chem. Rev. 1998, 98, 1743-1754.

3. Hamley, I. W.; Deshsorkhi, A.; Castelletto, V. Chem. Commun. 2013, 49, 1850-1852. 